\title{
EN TORNO A COLÓN
}

\author{
POR \\ JuAn Adolfo VÁzQuez \\ University of Pittsburgh
}

Rumeu de Armas, Antonio. Libro copiador de Cristóbal Colón. Tomo I: Correspondencia inédita con los Reyes Católicos sobre los viajes a América. Tomo II: Transcripción. Madrid: Testimonio Compañía Editorial, 1989.

Greenblatt, Stephen (editor). New World Encounters. Berkeley and Los Angeles: University of California Press, 1993.

ZAMORA, Margarita. Reading Columbus. Berkeley and Los Angeles: University of California Press, 1993.

Stavans, Ilan. Imagining Columbus: The Literary Voyage. New York: Twayne Publishers, 1993.

Correspondiendo aproximadamente con el famoso quinto centenario han aparecido numerosas obras en torno a Colón, sus viajes, sus escritos, y la significación histórica y literaria del "descubrimiento". Una de las publicaciones más importantes es la edición del libro copiador de Colón, ignorado por siglos, cuyo contenido consiste en su mayor parte en materiales que allí aparecen impresos por primera vez.

La historia del libro copiador es oscura. En su introducción al primer tomo del Libro copiador de Cristóbal Colón Antonio Rumeu de Armas nos informa que el original fue comprado por el Estado español a un librero anticuario de Tarragona "por un elevado coste", y que ahora se encuentra en el Archivo de Indias de Sevilla. Aunque nos da el nombre del librero y de la librería, Rumeu no dice cuándo se conoció la existencia del libro copiador, ni en qué momento se efectuó la transacción. Se calcula que las copias fueron manuscritas a mediados del siglo XVI, es decir, quizá cincuenta años después de la muerte de Colón. "Un rumor, no confirmado, señala como depósito originario una biblioteca de la isla de Mallorca". Lo más interesante del libro copiador es, naturalmente, lo que contiene, es decir las copias de cartas enviadas por Colón a los Reyes Católicos, según el siguiente detalle:

1. Carta-relación escrita hacia el final del primer viaje, cerca de Portugal, "en la mar de España, a quatro días de março de mill y quatroçientos y noventa y tres años". Este documento - la primera noticia, oficial y reservada, como el diario de abordo- difiere en tono y, parcialmente, en contendio, de otras sobre el "descubrimiento" enviadas por Colón a sus amigos los funcionarios de la Corte Luis de Santángel y Gabriel Sánchez, célebres 
porque se publicaron y tradujeron a varias lenguas europeas poco después. En el relato de esta carta inédita Colón oculta la pérdida de la Santa María diciendo que la dejó con gente en la villa de La Navidad.

2. Carta-relación sobre descubrimientos del segundo viaje, y colonización de La Española. Sin fecha, probablemente escrita a fines de 1494. Colón admite que la destrucción de la villa de La Navidad y los daños sufridos por "nuestros christianos" fue culpa de ellos por no haber seguido sus instrucciones de "que sobre todo dexasen las mujeres ajenas". La tres cartas que siguen también se refieren al segundo viaje.

3. Carta-relación en la que Colón puntualiza el viaje de exploración, por tierra, de la provincia de Cibao (La Española). Sin fecha, escrita probablemente alrededor del 20 de abril de 1494. Colón se demora en descripciones geográficas y pseudo etnológicas. Como en el diario del primer viaje y otros textos, añade, con aparente ingenuidad, que la gente de esa tierra "es la más mansa y temerosa y de buena condiçión que ay en el mundo" y "para que todos sean christianos" sólo le falta predicarles en su lengua, "porque es verdad que ninguna idolatria tienen".

4. Carta-relación en la que Colón informa sobre el viaje exploratorio de las islas Española, Cuba y Jamaica, escrita en Puerto de Santa Cruz a mediados de septiembre de 1494 en Isabela (capital de La Española) el 26 de febrero de 1495. Su contenido abarca desde el 24 de abril de 1494 hasta el 29 de septiembre del mismo año. Según Rumeu de Armas esta carta prueba que Colón no conocía la famosa obra de Sir John Mandeville (escrita en francés y publicada entre 1357 y 1371, de la que hubo traducciones latinas, inglesas, etc., que circularon en manuscrito) vertida al castellano como Libro de las maravillas del mundo en 1483. Rumeu afirma que Andrés Bernáldez, cura de Los Palacios, en sus Memorias del reinado de los Reyes Católicos dedicó desmesurada extensión al segundo viaje aprovechando la carta-relación de febrero de 1495 más otros escritos que le dejó Colón y datos tomados del doctor "Chanca y otros cavalleros que con él fueron en los viajes ya dichos, que escribieron lo que vieron". Asevera Rumeu que las reiteradas alusiones de Bernáldez al Libro de las maravillas se deben a un "vano alarde de erudición", sin base en la carta del almirante, donde no aparece el nombre de Mandeville ni el de su Libro. A mi entender, este argumentum ex silentio no prueba que Colón no conociera la existencia del libro de Mandeville, muy leído en la Europa del siglo XV y traducido al español poco antes de los viajes colombinos.

5. Carta-relación del segundo viaje de exploración terrestre de la isla Española, entre septiembre de 1494 y octubre de 1495 . Este documento se refiere, entre otras cosas, a una larga enfermedad de Colón ("muy grave" según su hijo Fernando), al apresamiento del cacique Cohonaboa, acusado de haber dirigido la destrucción de la villa de La Navidad; pero Colón no cuenta las artimañas de que se valió Alonso de Ojeda para apresarlo. Describe la batalla de La Maguana, que aseguró definitivamente la conquista de la isla, que Rumeu expresa diciendo: "Desde ese momento una inalterable paz reinó en toda la isla Espanola". La relación hace muchas referencias al oro, permanente obsesión colombina, con exageradas declaraciones acerca de la cantidad encontrada. Termina aludiendo a la llegada del visitador Juan de Aguado.

6. Carta-relación sobre el tercer viaje y la exploración de la costa norte de América del Sur. Sin fecha, presumiblemente escrita en septiembre de 1498. Las Casas consigna 
que fue despachada el 18 de octubre e iba acompanada de un mapa ("figura o pintura"). Este documento fue dado a conocer por Martin Fernández de Navarrete en su Colección de los viajes y descubrimientos que hicieron por mar los españoles desde fines del siglo $X V(1825)$, basándose en la copia de Las Casas, que ahora se encuentra en la Biblioteca Nacional de Madrid. Ha sido utilizada por muchos autores. Como el texto registrado por el libro copiador difiere en muchos pasajes del texto lascasiano, Rumeu confronta en dos columnas paralelas las variantes. Una de las ideas más curiosas expuestas por Colón su concepción de la Tierra, a la que atribuye forma de pera, con el Paraiso terrenal en su parte más alta y de más difícil acceso. Colón está persuadido de haber llegado muy cerca del Paraiso "porque todos dicen que está en fin de oriente".

7. Breve carta de Colón a los Reyes, anexa a la copia de la primera carta, de 1493. Colón se queja del mal trato que ha recibido. "Fecha en la ysla Española, olin Ofir, a tres días de febrero 1500". La copia dice 'olin' por olim ('antiguamente' en latin). Ofir, muy citado en el Antiguo Testamento, era un lugar indeterminado de Oriente, de donde provenían oro y otras cosas de alto precio. En una postdata del 20 de noviembre del mismo año Colón confiesa que no sabe por qué los Reyes han mandado al contador Bobadilla a ponerlo preso y enviarlo "cargado de fierros". La carta incluye muchas reflexiones inspiradas en textos del Antiguo Testamento.

8. Carta a los Reyes enviada desde la Española con la misma fecha que la anterior. Colón se queja de la falta de respuesta a sus cartas: "Yo he siempre scripto a Vuestras Altezas todas las cosas de acá; paresze que mis cartas no llegaron a su alto conspecto, o que la rrudez de mis palabras o novedades de las cosas yncreibles y tenidas fabulosas, las desbiaron dello." Colón vuelve a enúmerar sus méritos y pide la confirmación del mando supremo de las fuerzas militares que, según él, deben ir a rescatar de los musulmanes la Tierra Santa de Jerusalén.

9. Carta-relación del cuarto viaje de descubrimiento. Refiere la exploración de América Central; escrita en Jamaica el 7 de julio de 1503. Lo mismo que el documento número 6 del libro copiador, esta carta ya era conocida por formar parte de la colección de Navarrete, y aún antes, por una versión italiana impresa en Venecia (1505); pero perdida de vista hasta 1810, cuando fue reimpreaa como Lettera rarissima de Christophoro Colombo. El manuscrito utilizado por Navarrete es una copia existente en la Universidad de Salamanca, de la que Cesare de Lollis hizo una excelente edición en su gran Raccolta Colombiana (1892-1894). Colón narra su exploración de las costas caribeñas de América Central en busca de lo que entonces se llamaba Aureo Chersoneso, hoy Malasia. En cierto momento Colón cree estar próximo al Ganges. Como sus naves hacen agua, trata de volver a La Española, pero sólo consigue arribar a Jamaica (25 de junio de 1503). El almirante envió esta carta con su colaborador Diego Méndez y su compatriota Bartolomé Fieschi, pero oculta sus nombres diciendo: "Esta carta enbio por bia y mano de yndios; grande maravilla será si alli llega". Los diez indios remeros con Méndez y Fieschi lograron alcanzar La Española, desde donde el gobernador Nicolás de Ovando la reexpidió a los Reyes por mano del mismo Diego Méndez. Como en el caso del sexto documento, Rumeu efectúa un detallado cotejo a dos columnas de las principales diferencias entre el texto del libro copiador y el del manuscrito salmantino. Aunque en general más completo, el copiador omite algunas líneas que pueden leerse en la copia de Salamanca. 
En suma, la colección de cartas dada a conocer por la publicación de la obra titulada Manuscrito del Libro Copiador de Cristóbal Colón es de gran valor histórico y documental. Su comentarista, Antonio Rumeu de Armas, ha realizado una tarea utilísima no sólo por la transcripción paleográfica de los textos sino también por los detenidos comentarios que ocupan el primer tomo de la obra, a través de capítulos que siguen un orden cronológico, con extensos excursos aclaratorios de contextos no explícitos en las cartas. A veces no es fácil correlacionar los comentarios de Rumeu con los textos transcriptos porque la secuencia de los comentos no es la misma que la de los documentos. Rumeu agrupa primero las aclaraciones a los manuscritos inéditos, luego a los ya conocidos. Asimismo, la correlación entre los comentarios del primer tomo y las piezas del segundo habría sido más visible si se hubieran juntado unos y otros en cuatro series correspondientes a los cuatro viajes. Por otra parte, en el segundo tomo, dedicado a la transcripción paleográfica de los documentos, echamos de menos todo título o subtítulo. Aun el índice sólo reza "Documento I", "Documento II", etc. Habituados a las buenas ediciones inglesas y norteamericanas, también lamentamos la falta de un pormenorizado índice de autores citados y temas del primer tomo, cuyo extenso índice general no cumple las funciones del que deseamos.

Otra extraña particularidad de esta edición es el texto firmado por Jorge Semprún Maura, Ministro de Cultura, intercalado sin título alguno entre la portada y la introducción de Rumeu de Armas. Se refiere allí el ministro a "este facsímil, realizado con las más perfectas técnicas de impresion que se conocen y con el esmero y cuidado con los que, afortunadamente, trabajan todavía nuestros profesionales de las artes gráficas". Como los dos tomos titulados Libro Copiador de Cristóbal Colón circulan sin el acompañamiento de la edición facsimilar, el texto, resulta enigmático si no se sabe que ambos volúmenes y el facsímil forman parte de una sola obra que puede consultarse en las pocas bibliotecas que han podido adquirirla. (Una de ellas es Hillman Library, de la Universidad de Pittsburgh. Los dos tomos que he manejado me llegaron aparte.)

El volumen compilado por, Stephen Greenblatt bajo el título de New World Encounters se suma a la reciente ola de estudios sobre el renovado contacto de culturas y civilizaciones promovida por los viajes de Colón. En su reseña introductoria Greenblatt destaca las características de los artículos que componen este libro diciendo que "tienen como interés central lo que Nathan Wachtel llamó 'La visión de los vencidos"”. (En realidad, antes que Wachtel, Miguel León Portilla había publicado en 1959 un volumen titulado precisamente Visión de los vencidos, cuya traducción inglesa, editada en 1962, se llama The Broken Spears.)

Los trabajos incluidos en New World Encounters son: Christopher Columbus's "Letter to the Sovereigns", announcing the Discovery, por Margarita Zamora; "Fierce and Unnatural Cruelty", Cortes and the Conquest of Mexico, por Inga Clendinnen; The Negotiation of Fear in Cabeza de Vaca's Naufragios, por Rolena Adorno; Ius et Factum: Text and Experience in the Writings of Bartolomé de Las Casas, por Anthony Pagden; Demons, Imagination and the Incas, por Sabre MacCormack; The Philosopher's Breviary: Jean de Léry in the Enlightenment, por Frank Lestringant; The Aesthetics of Conquest: Aztec Poetry before and after Cortés, por David Damrosh; Dancing and the Sacred in the Andes: From the Taqui-Oncoy to Ras-Ñiti, por Sara Castro-Klarén; The Work of Gender 
in the Discourse of Discovery, por Louis Montrose: Ralegh's Fugitive Gold: Reference and Deferral in The Discovery of Guiana, por Mary C. Fuller; Voices of Resistance: The Epic Curse and Camoes's Adamastor, por David Quint; Elizabethan Tobacco, por Jeffrey Knapp; Epilogue: Michel de Certeau's Heterology and the New World, por Luce Guard; Travel Narratives of the French in Brazil: Sixteenth to Eighteenth Centuries, por Michel de Certeau. Todos estos trabajos se habían publicado en diversos números de Representations (1991), salvo el de Sara Castro-Klarén, que apareció en Dispositio (1989) en una versión distinta, y el de Margarita Zamora, que aquí se imprime por primera vez.

Coincido con Margarita Zamora en juzgar que la publicación del Libro copiador "es probablemente el acontecimiento académico más importante del Quinto Centenario". Como la autenticidad de las cartas dirigidas a Luis de Santángel y Gabriel Sánchez ha sido muy controvertida, y no aparecen en el libro copiador, la carta-relación a los Reyes del 4 de marzo de 1493 adquiere aún mayor importancia. Comparando el texto de las cartas a Santángel y Sánchez, Margarita Zamora señala que "mientras las descripciones de la tierra y las gentes que han hecho famosa la versión Santángel-Sánchez no son muy diferentes de las que aparecen en la carta del 4 de marzo a los soberanos, la interpretación que esta última asigna a la empresa es distinta, como lo es su discusión de algunos problemas que tuvo la expedición, tratados en forma mucho más franca, aunque discretamente".

Los problemas aludidos son sobre todo los siguientes: la información que pudiera servir a los competidores, por ejemplo las ventajas de la carabela, más ligera que la nao, para viajes de exploración; hechos que desacreditarían la expedición, como la encalladura de la Santa María (en verdad, Colón no menciona la pérdida de la Santa María) o la insubordinación de Martín Alonso Pinzón; las peticiones de Colón a la Corona para que le acuerden los privilegios que le habían prometido; planes para vincular la empresa del descubrimiento a una proyectada reconquista de la Tierra Santa y la liberación de Jerusalén.

La carta, dice Margarita Zamora, "representa inequívocamente al Descubrimiento como una aventura comercial conjunta entre un individuo impulsado por ambiciones mundanales y espirituales, y el Estado, que por contrato estaba obligado a compensarlo por la iniciativa y se beneficiaría por sus esfuerzos". La autora concluye afirmando que no es ésta la imagen del Descubrimiento o el retrato de Colón al que estamos acostumbrados. Posiblemente Margarita Zamora piensa en la leyenda colombina que se solía enseñar en las escuelas; pero a mi modo de ver nada hay en esa imagen que no se perciba también en otros textos bien conocidos, como el diario del primer viaje.

La frase "visión de los vencidos" no corresponde a la mayoría de los trabajos recogidos en New World Encounters, que se basan mayormante en el testimonio de los vencedores, por que éstos son siempre los que escriben la historia. Uno de los pasos que pueden darse para superar la unilateral visión de los triunfantes consiste en ampliar el radio de los encuentros yendo más allá del siglo XVI y principios del XVI. Como se ha dicho, el descubrimiento y la conquista de América aún no han terminado, y la resistencia a la conquista tampoco ha terminado. El trabajo de Sara Castro-Klarén - que trata del rito de Taqui-Onco, la leyenda de Inkarrí y el cuento de Arguedas "La agonía de Rasu-Ñiti"abona en favor de esta tesis. Mucho podría agregarse tomando en cuenta el testimonio de grupos indígenas de regiones poco a nada aculturadas de México, América Central, la Amazonia, el Chaco y la Patagonia, que por prejuicios europeizantes se las llama "marginales". 
Para hacer justicia a la visión indígena de los encuentros es necesario, por un esfuerzo de imaginación, reconstruir la concepción del mundo de los indios, cosa que no puede lograrse atendiendo solamente a escritos europeos, como ocurre en el trabajo de Rolena Adorno - por lo demás muy interesante-quien se pregunta qué querían decir los indios cuando manifestaban que los invasores eran gente venida del cielo. Rolena Adorno rechaza, con razón, las interpretaciones que ven en esa frase "una premonición o intuición del Cristianismo, interpretando ese concepto como 'celestial' o divino en sentido cristiano". En su opinión, los indios sólo querían decir que era "de origen desconocido". Por otra parte, después de citar los brutales homicidios perpetrados por ciertos conquistadores, añade que no quedó entre los indios ninguna duda acerca del valor negativo de los invasores que, si bien "tenían poderes mágicos y extraordinarios, mal podían ser vistos como los visitantes celestes largamente esperados. Más bien eran agentes de muerte y destrucción".

Esta lectura no tiene en cuenta el hecho, reiteradamente comprobado, de que para las sociedades preindustriales el cielo es un espacio sagrado de donde vienen todas las cosas importantes. La concepción cristiana del cielo como algo divino es sólo un caso particular de una creencia vigente en plurales comarcas y épocas. Pero no todo lo que viene del cielo es, humanamente hablando, positivo; puede ser malo para el hombre. Aun así, por ser extraordinario y poderoso se lo considera también como divino. Característica de lo divino es la paradójica coincidencia de opuestos: ira terrible y dulce misericordia. No es propio de las religiones aplicar a lo divino patrones válidos para el conocimiento y comportamiento humanos. E1 misterio teológico rebasa los límites de la razón y las normas éticas obligatorias para los mortales. Desde luego, esto no es nada que a mí se me ocurra o que me agrade. Tampoco es nada novedoso: así lo cree la experiencia religiosa de la humanidad.

En su libro Reading Columbus Margarita Zamora retoma la carta a los Reyes del 4 de marzo de 1493 junto con otros textos colombinos, especialmente las capitulaciones o contratos celebrados entre Colón y los Reyes, y el cuaderno de bitácora del primer viaje. Zamora cree que el breve prólogo que precede al diario de abordo es un texto independiente -más precisamente, una carta- que Las Casas colocó - "si es que no fue totalmente inventado por él- al principio para darle más valor, así como también añadió al texto frases como "esto que se sigue son palabras del Almirante en su libro de su primera navegación y descubrimiento de estas Indias". Según Margarita Zamora Las Casas manipuló el texto del diario para publicarlo como testimonio en favor de sus propios intereses. La autora usa más de una vez la palabra edit que - como sin duda sabe el lector- no corresponde al español 'editar' (es decir, 'publicar') sino a preparar originales para la imprenta, corrigiéndolos, suprimiento palabras, frases o párrafos enteros, y añadiéndoles otros según crea conveniente. No hay duda de que Las Casas resumió parte del texto que leyó en una copia, y en parte lo dejó tal cual indicándolo, a falta de comillas, que todavía no se usaban, con frases como la que he transcripto. También es verdad que Las Casas intercala comentarios; pero lo hace al correr de la pluma, sin ocultar que es él quien los escribe. Otras veces pone al margen signos para llamar la atención del pasaje, o breves juicios, algunos de franca censura. Según Zamora habría que incorporar al texto las anotaciones marginales, convirtiendo todo el manuscrito lascasiano en una sola pieza literaria suya. Recomendación desatinada. 
No es posible tratar en pocas líneas los argumentos que Margarita Zamora esgrime con admirable despliegue de erudición y dominio del análisis de palimsestos, tratando de probar que las Casas se tomó toda clases de libertades con el texto a fin de publicarlo en apoyo de sus ideales morales y evangélicos. A pesar de todos sus esfuerzos, a mi juicio Zamora no consigue refutar la opinión tradicional de que el texto lascasiano del diario consiste en apuntes que fray Bartolomé escribió al leer una copia no muy clara del original hoy perdido, y que los resúmenes, paráfrasis y citas, así como sus propios comentarios, fueron materiales para su Historia de las Indias, donde efectivamente los utilizó. Hay muchas maneras de tomar notas de estudio. Una de ellas es la de Las Casas. Los textos abreviados, citados, comentados, en un cuaderno de trabajo, no deben considerarse manipulados para engañar al lector en una edición fraudulenta.

Uno de los capítulos más sugestivos y menos controvertibles de Reading Columbus es el titulado "Voyage to Paradise", motivo folklórico estudiado por etnólogos e historiadores de las religiones aquí ausentes. El tema, muy amplio, invita a examinar cartas medievales del Atlántico no reproducidas entre las que este libro exhibe sin mucha nitidez. Se vería entonces por qué Colón esperaba encontrar islas antes de llegar al continente asiático, además de la Antilis que aparece en tantos portulanos. Colón era demasiado buen piloto para dejarse tentar por las antiguas mitologías de las islas; buscaba decididamente tierra firme. Pero a último momento, poniendo proa a España al final del primer viaje, lamenta no tener tiempo para buscar la Isla de las Mujeres sin hombres, de las amazonas que, creía haber entendido en el Caribe, estaban allí cerca.

Este tema recuerda el capítulo de Reading Columbus titulado "Gender and Discovery", que comienza con una descripción o interpretación de un grabado de Theodor Galle, de fines del siglo XVI. Según Margarita Zamora, la ilustración muestra una india desnuda que se está incorporando de su hamaca para abrazar a un europeo recién llegado, o que se está reclinando para inivitarlo a acostarse con ella. Yo diría que la mujer, sorprendida en su descanso, y asustada al descubrir un inesperado visitante pesadamente ataviado con ropaje que sólo deja ver sus manos y su cara, expresa asombro. El contraste entre el europeo vestido y la americana desnuda no tiene por qué ser interpretado como una representación erótica: era un hecho vulgar y cotidiano en el Caribe de los conquistadores. Además ¿por qué limitarnos a América? Todos los continentes tienen nombres de mujer y las figuras femeninas que los representan pueden andar con poca ropa. Europa raptada por el toro sagrado no iba más vestida que la indígena americana.

Estos reparos no disminuyen ni el valor de la insólita cantidad de información que Margarita Zamora maneja con soltura ni el estímulo intelectual que sus interpretaciones provocan. Libro nuevo y original, Reading Columbus merece atenta lectura.

En Imagining Columbus Ilan Stavans sostiene que si bien es cierto que es imposible conocer en su totalidad la vida de Colón (¿y de quién podemos conocer su vida en detalle?), gran parte de su biografía puede distinguirse perfectamente de las ficciones que en torno a ella se han tejido. Su libro, añade Stavans, tiene por objeto retomar, investigar y "jugar con las geometrías asimétricas de las aventuras literarias del almirante en la imaginación humana". Imagining Columbus, nos dice su autor, es "un enorme tapiz donde los rumores colectivos y las consejas que me contó mi abuela, y otras que encontré después, se entretejen 
con mis intereses personales". Pero en seguida admite que no le interesa la historia. "Me interesa la ficción, no la historia; la literatura, no la información verificable".

Parecería, por tanto, que la distinción establecida al principio entre la documentación histórica irreprochable (que el autor llama facts on file) y las construcciones de la imaginación no es importante. Hasta cierto punto el autor tiene razón, porque los facts on file no dicen nada por sí mismos. Sólo comienzan a ser inteligibles si son imaginativamente reconstruidos en la trama del historiador. Clío era una musa. Pero existe una importante diferencia entre la imaginación histórica que se inspira en datos positivos (facts on file) y la deliberada ficción que mezcla indistintamente testimonios fidedignos, patrañas legendarias y libres ocurrencias de la fantasia. Estas creaciones pueden ser, según suele decirse, muy divertidas, y aun poseer calidad estética como obras literarias de ficción; pero oscurecen la diferencia que Stavans establece al comienzo de su libro, confundiendo diversos géneros de aventuras intelectuales. Cualquier cosa resulta ser igual a cualquier otra.

Dice Stavans que muchas páginas de Imagining Columbus aparecieron originalmente como ensayos o reseñas bibliográficas. Pero sus fuentes de información son en realidad enciclopédicas. El libro comienza con la biografía de Cristóbal Colón por su hijo Fernando y llega hasta el Cristóbal nonato de Carlos Fuentes, concluyendo con algunos ejemplos de ficiones que podrían escribirse en el siglo XXI. La bibliografía, de más de 200 títulos, es, naturalmente, una lista heterogénea de obras muy diversas, como corresponde al contenido del libro y a la cronología que registra en una enumeración caótica hechos ocurridos entre 981 y 1992, como la publicación del Quijote y el escándolo de Watergate.

Nadie debe negar al escritor la libertad de escribir lo que se le antoje; pero conviene alertar al lector sobre el uso tendencioso o simplemente equivocado de las palabras. Por ejemplo, Stavans afirma que los taínos se amotinaron (xv) y que los geógrafos contemporáneos de Colón creían que la Tierra era plana (117). ¿Es que para nuestro autor estos juicios son válidos, no importa qué digan los facts on file?

Imagining Columbus es una curiosa galería de cuadros colombinos pintados por diversos escritores. No intenta Stavans basar sus posibles retratos en los documentos que dejó Colón, como los pacientemente presentados por Antonio Rumeu de Armas o críticamente interpretados por Margarita Zamora, que justifican mantener la distinción entre imaginación histórica y fantasía literaria. 